Journal of Teacher Education for Sustainability, vol. 19, no. 2, pp. 154-164, 2017

\title{
Education towards Urban Sustainability: Lessons Learned from the Welfare Business Models of Kanazawa City, Japan
}

\author{
Aida Mammadova \\ Kanazawa University, Japan
}

\begin{abstract}
Education is considered a driving force for urban sustainable development and there is an urgent need to use different approaches to increase the awareness level in younger generations. Teaching about sustainability requires an integrated approach due to its complex concept, and in this study to show the interconnection of the social, environmental and economic sectors of the city the author decided to conduct fieldwork activities in the welfare business sectors, which is one of the leading practices used in the aging Japanese population. Japan's population is aging with a declining birth rate, and the country is becoming a "super-aging" society with one out of every four persons aged above 65 years. There are crucial issues to provide social services, such as care for the elderly, child support programmes to reduce the child-raising anxieties, care for mentally and physically disabled people and others. In this study, the objectives were 1) to provide the fieldwork in small-scaled private and town-scaled business sectors and 2) to observe the interconnection of urban sustainability practices through the welfare with environmental, social and economic sectors. Private and public sectors were visited by 15 international students with different educational backgrounds, who had no idea about urban sustainability. In total, four welfare business sectors were visited by the students: two sectors were related to the farming activates together with care for disabled people, and the other two field trips were related to urban community-development business sectors. After the field trips, students evaluated a linkage among social, environmental and business sectors related with welfare practices. The awareness level of the students increased $(85 \%)$ towards the issue of sustainable urban development, and they were able to provide the recommendations for the inclusive, safe and resilient cities. These field trips showed very positive feedback, to educate the youth. In this study, the author presents the qualitative transdisciplinary field trip approach. However, to improve the methodology a cohort analysis with a quantitative data analysis will be performed in the further study.
\end{abstract}

Keywords: urban sustainability, education, welfare, field trips, community-oriented business 


\section{Introduction}

Urban areas are facing major challenges such as demographic growth, environmental changes, economic crisis, and social issues, and there is an urgent need to raise the awareness of those issues as the population of the cities is increasing annually in the world. The main issue that impedes sustainable development is the lack of awareness of the present issues, especially in young generations who live in the cities. Education is considered a driving force for urban regeneration; however, in the age of rapid globalization, conventional teaching and pedagogic approaches used in the past may not be suited for the modern generations. Moreover, educators are facing many challenges in teaching sustainability as the subject. Sustainability has numerous definitions in different fields, and due to the diverse and sometimes even unclear terminology, it creates various interpretations in the world of science, economy, society and education. We cannot argue that the concept of sustainability has a clear meaning in a particular framework, however enforcing "sustainability" as a goal, makes the idea very obscure and questionable in higher education (Wals \& Jickling, 2002). Some studies in the field of sustainable education have already evaluated the transdisciplinary research framework by integrating the experiential practices with the theoretical ideas, which will deepen and extend the education quality achievement towards sustainability and sustainable development (Salite et al., 2016) by creating the methodology which will allow for the reintegration of the knowledge and creating a new science (Sommerville \& Rapport, 2002). The complexity of the sustainability education system is also related to the complexity of social systems and research paradigm (Pipere, 2016), and represents the highly conceptualized situations and subjects.

Educational institutions are facing many difficulties in conducting sustainable development studies in higher education because there is no specific methodology and/ or guidance. Many questions should be addressed, such as: In which particular directions should learning take place, as the definition itself is not clear? To what extend must higher education be involved in the local issues related to the Sustainable Development Goals (SDGs)? How far can participatory approaches be conducted within the educational framework to reach SDGs? What missions and objectives of the teaching and research programmes should be implemented to reach the SDGs, and to what extent should they be conducted?

Since 1992, after United Nations Conference on Environment and Development (UNCED) in Rio de Janeiro (the so-called "Earth Summit") the concept of sustainable development was widely accepted by the countless international organisations, national institutions, enterprises and local communities (Hawken, 2010). In 2016, seventeen SDGs were adopted by the United Nations, and Goal 11 "Make cities and human settlements inclusive, safe, resilient and sustainable" was confirmed to achieve urban sustainability with opportunities for all, with access to basic services, energy, housing, transportation and others. However, the question how we can achieve those goals is a major issue, and it requires the involvement of every person with a bottom-up approach. It should be noted that not all environmental, social or economic issues are solely about sustainability and its goals, as they are rather issues related to the human-nature interrelationship, cultural identities and basic human values (Murray, 2011).

Hence, due to the complexity of the concept of sustainability, teaching about sustainability would also require an integrated and complex approach (Robertson, 2014), as it encompasses social, economic, cultural, ecological, ethical and spiritual aspects of all 
our life. The extent of its application depends on how well the educators are familiar with its diverse concepts. Besides, sustainability cannot be fixed, and due to constant environmental changes, sustainability would change from situation to situation and over time, so academic programmes should be always renewed and reconsidered, as well as appropriate for teaching urban sustainability.

However, unlike many uncertainties, higher education still has a huge potential and capabilities to integrate sustainability studies, and create more diverse, participatory and independent approaches, without standardising the ideas and attributing only to the goals. Studies for sustainability can bring many benefits, by creating the diverse curriculum, study programmes or subjects with diverse ideas. This kind of an integrated educational approach with diverse goals and directions can help educate the generations with a wide range of viewpoints, increase the ability for independent and critical thinking as well as develop students' own potential by becoming the self-actualized members of the society.

In the developed approaches to teach about sustainability, the author has previously created several and diverse education field trips. To raise the awareness of urban sustainable development, the author has conducted fieldwork activities where the author linked the biodiversity with the cultural diversity of Kanazawa City, and monitored the importance of the human capital for the preservation and management of the natural resources (Aida \& Iida, 2016). Besides, the author has conducted SDG training courses and evaluated the sustainability levels of the city's environmental and economic sectors, and monitored how those sectors depend on each other and function in an integrated manner (Mammadova, 2016). From the previously conducted studies, the author has found the importance of the communities that supports the idea of "benefit sharing" and "creating shared values" with each other for the sustainable regional development. Japan's population is aging with a declining birth rate, and the country is becoming a "super-aging" society with one out of every four persons aged above 65 years. There are crucial issues to provide social services, such as care for the elderly, child support programmes to reduce the child-raising anxieties, care for mentally and physically disabled people and others. However, unlike all those issues Japan is creating the mutually supporting communities, where no one is left behind, and applies integrated collaboration to provide social services for all inside the community. Social welfare practice of Japan is one of the most successful practices conducted inside the country. Governmental support together with the involvement of the small business, local residents, volunteers and welfare service providers is all included to work in collaboration with each other to create the mutually shared community. Therefore, in this study to raise the awareness of the importance of the integrated approach towards sustainable urban development, the author decided to create the fieldwork activates inside the most successful practices of Japan, such as social services and welfare related business sectors of the City.

Welfare business sectors gradually imply the concept of community-based strategies in "creating shared values" (CSV) for all (Porter \& Kramer, 2011). The business and management sectors of the City increasingly recognise the importance of the welfare and community-based business strategies, and the ideas of CVS and "corporate social responsibility" (CSR) are implemented almost in each urban business sectors of Japan (D’amato, Henderson \& Florence, 2009; Tanimoto \& Suzuki, 2005). Big companies and business sectors have created a negative image due to their harmful effects on the environment and society; however, businesses conducted in the proper way can be the 
leaders to achieve sustainable development. One of the successful sustainable business practices for sustainable development is the business that cares about the improvement of the life of a community. The so-called community-based business development models with CSV were introduced by Michael Porter (Porter \& Kramer, 2011), who was stressing that companies through their business activities should provide social solutions to the local communities and be an essential part of the community. CVS and CSR activities have been used in the Japanese society for a long time, and all business sectors are constantly implementing the CVS in their management system and company's regulations as an "indispensable" part. Almost each company in Japan recognises the social contribution as the fundamental basis for the successful business management, and sets the goals to achieve prosperity in accordance with the public interests and public values (Nonaka \& Takeuchi, 1995). Business models that contribute to the society are crucial in making differences towards sustainable development, by providing valuable, innovative products and services, employment, education and training opportunities.

In the subsequent sections, the author will discuss four Welfare Business sectors visited by the students and evaluate the linkage of the welfare business practices for sustainable urban development inside Kanazawa City of Japan. Kanazawa City's population is almost half a million people, and the city has several very successful welfareoriented business practices implemented at the private and governmental levels.

\section{Methodology}

The intensive fieldwork was conducted from April to June, during the spring semester at Kanazawa University. Participants were 15 international students with different backgrounds. Only the students who visited Kanazawa City for the first time, and had no information about urban issues were selected to participate in the course. At the begging of the fieldwork, students were given the basic lectures about sustainability, social structure and environmental features of the region.

\section{Design of the Field Trips}

Fieldwork was divided into four destinations and conducted every month together with the introduction lectures on welfare and sustainability. Field destinations were divided into the four main sectors with destinations described in Table 1 . The objectives were 1) to provide the fieldwork in small-scaled private and town-scaled business sectors and 2) to observe the interconnection of urban sustainability practices through the welfare within each sector. The first two field trips were related to the farming activities together with care for disabled people, and the other two field trips were related to introduction to the successful urban community-based development models implemented inside the city. At the beginning of the course the author decided to introduce the smallscaled and private sectors in agriculture and care practice, such as Chihara and Rehas Farms, because they could raise the awareness on the issues of depopulation, aging, field abandonment and land management. As the outcomes, students would be able to learn effectively how the care for disabled people could benefit for the regional land revitalization with small employment opportunities and observe the care practices conducted in the welfare sectors for the disabled people. After the introduction of small business sectors, the author decided to show the macro-scale of the sustainable urban 
town model with the main community-based care practices, such as the case of Taiyougaoka town and Share Kanazawa town models. These kinds of town models show the integrated approaches towards urban sustainability and provide the perfect educational practice for the students to experience all environmental, social and economic issues in the interconnected and interdependent manner. Students were able to observe and analyse how each sector was related to the other, and the loss or change in one of the practices would create the chain reaction and affect other members inside the community.

During each course, students conducted the interviews with the local people, owners of the business sectors and welfare workers. They were requested to find and record the interconnection of each destination with other social, environmental and economic sectors of the city. After the course, students submitted reports in which they described the following: 1) connection of each sector with other urban sectors; 2) benefits and issues related to social care services. The survey was conducted among the students to evaluate how the field trips raised awareness of the issues related to sustainable urban development. At the end of the course, the workshop was organised by inviting the professional speaker in the field of welfare, and students were requested to create the model of an inclusive, resilient, safe and sustainable city.

Table 1

Visited Sectors

\begin{tabular}{lll}
\hline \multicolumn{1}{c}{ Field Trips } & \multicolumn{1}{c}{ Destinations and Goals } \\
\hline 1 & Chihara Farm & Private business farm for Asperger syndrome children \\
\hline 2 & Rehas Farm & $\begin{array}{l}\text { Rehabilitation centre + social activities and employment opportunities } \\
\text { for people with disabilities }\end{array}$ \\
\hline 3 & $\begin{array}{l}\text { Taiyou-gaoka } \\
\text { Town }\end{array}$ & $\begin{array}{l}\text { Town with all facilities for three generations to live together in one } \\
\text { community }\end{array}$ \\
\hline 4 & Share Kanazawa & $\begin{array}{l}\text { Town with all facilities for inclusive lifestyle of the community, mainly } \\
\text { conducted by the elderly people and people with disabilities }\end{array}$ \\
\hline
\end{tabular}

\section{Brief Description of the Visited Sectors}

Chihara Farm: The small farmland that is owned and managed by the local businessman who provides the three main activities for the regional development such as: 1) providing employment for disabled people by working in collaboration with NPO of "Ishikawa Association for Asperger Children" and providing the individual care for them through the blueberry cultivation; 2) making vegetables and food products as "the ultimate food supplements", without using any pesticide or chemical fertilizer; 3) regional revitalization by utilization of the abandoned farmlands and attracting more people for regional revitalization.

Rehas Farm: The rehabilitation farm that belongs to the "Creators Inc" Company. The company provides the employment for the disabled people by creating a business opportunity in four pillars: design and creativity, cleaning, food production and agricultural business. It is a facility for supporting employment based on the "Comprehensive Support Law for Persons with Disabilities”. They aim to provide employment opportunities to those who have difficulties in finding employment in general companies and to provide welfare services for people with disabilities. Company provides the "nonemployment type" contract with disabled people that allows them to work relatively 
freely. All employees with disabilities are under the constant care of professional occupational therapists. The work is mainly conducted in the herb farm, by planting and packaging the herbs.

Taiyo-gaoka Town: A small town inside Kanazawa City, which was established in 1992 by the local private company "Taiyo Planning Corporation" that decided to provide all social and welfare facilities for the new human settlements. The idea came to make a strong community-based town and bring all three generations of the families to live together. Japanese communities are facing a rapid decline because the population decreases and young people are leaving for big cities to pursue for higher education and employment. Taiyo-gaoka town provides all facilities for the human well-being starting from kindergartens, kid's colleges, schools, universities, clinics, pharmacies, elderly dayservices, wedding halls, leisure parks, football/sport grounds and many other facilities just within the area with 830 households and population of 2,533 people. All facilities were built in a very compact way with modern and traditional styles. Surprisingly, the average age of the residents is around \pm 33 years, which is considered to be very young in the whole Kanazawa City. It is an area designed specifically to accommodate families with young children and elderly parents, having care facilities for both, which enables people to continue to work while their family is cared for close by.

Share Kanazawa: Created by the local businessman, who has opened many facilities for the care of disabled and elderly people in the whole Ishikawa Prefecture. Share Kanazawa is the area with only 1.1 hectares and divided into South, Middle and North parts with shared rooms and housing facilities, public hot springs, Bars, Cafeterias, Music Halls, Town Cleaning centres, sport and relaxation centres and many others. Share Kanazawa is popular among non-residents as well as those who come to visit the community and spend the time in the friendly atmosphere. It is popular among the locals because of the strongest community-based CSV, as all the facilities are run and conducted by the local residents themselves, most of whom are people with physical or mental disabilities, university students or elderly. The housing rents are cheap compared to the other towns with many volunteering activities instead, where the residents constantly meet and communicate with each other. Persons without any discrimination can live and share community lifestyle.

\section{Field Trips Outcomes}

Kanazawa City was able to show a good practice for urban sustainability studies through fieldwork for the welfare business sectors. $85 \%$ of the students replied that the fieldwork helped raise the awareness of the issues related to sustainable urban development in Japan, such as depopulation, aging and urgent need of integrated activities with diverse environmental, social and economic sectors. The interconnected sectors and the model for inclusive cities were created with the following recommendations:

\section{Environment, Energy and Transportation}

Creating business sectors with locally made products and natural ingredients Encouraging cities to produce more local goods and services Caring and using one's own utensils for eating instead of disposable ones Less vending machines, unnecessary packaging, plastic bag and bottles Installing recycling machines with reward 
Increasing use of renewable energy

Rain harvesting and wave energy

Connecting the machines in gums to the energy generator and creating energy while exercising

No machines with stand-by mode

Creating more natural waste tanks inside the community to produce natural fertilizers for farming

Installing a recycling system in each corner of the city's blocks

More green space

Alternative and cheaper transportation

Accessible transportation for the elderly and disabled people

\section{Municipality, Police and Politics}

Lower tax rates for large companies and multinational corporations in exchange for assisting the area with renewable and affordable energy

Certification and reward system for volunteering inside the city

Creating "World Union Association" for working together towards the sustainable urban future

Returning back to the old trade system: e.g., one day volunteering on exchange to something

Creating community-based educational activities

Public health engineering, endemic plan

Promoting political interest in young people

Sustainability related reward giving, phone apps etc.

Creating SDGs controlling Police around the city

\section{Health Care, Elderly Care, Care for Disabled People}

Adequate health care access

Creating easy employment and work activities for the retired people

Increasing day service centres

Easily accessible facilities

Employment opportunities and no discrimination

Fair education for those with physical and mental disability

Art centres and therapy centres

Natural-labour maternity clinics

Preventive medicine centres

Public health care and education

\section{Academic Institution and Proper Education for All}

Sustainability courses in every school and for every level of students

Creating career and job search centres for the youth in the diverse sustainability sectors Creating annually practical sustainability activities in public and private business sectors,

local communities, hospitals, and social sectors

Care for disabled people in the business sectors showed the most positive results and was evaluated by the students in terms of the benefit for the society such as:

1. Renewal of health, as integral care within community reduces the stress level in people. 
2. Integration of disabled people into the society makes cities inclusive for all.

3. Independence and equal social status of disabled people.

4. Diversification of agricultural products.

5. Disability as an advantage instead of the limitation as people with disabilities show more willingness to work.

6. New source of income and employment that can boost local economy.

7. Huge potential for the regional revitalization in the declining society of Japan.

Still in Japan, disability is considered the limitation and one of the students in his report explained how inspiring it was to see people with disabilities working in café and providing services for the customers in Kanazawa: “The 2013 study entitled "Review of Mental-Health-Related stigma in Japan" (Ando, Yamaguchi, Aoki \& Thornicroft, 2013 ) states that $61 \%$ of employers would not consider employing someone with a history of mental health illness. And only $20 \%$ of psychological professionals believed that people struggling with mental illness do not require hospitalization to recover. Another research demonstrates that Asperger's is a very serious social handicap in Japan, and it is hard for those affected to be accepted. In one blog on which someone with Asperger's was seeking advice about his upcoming move to Japan, among the most popular responses was "hide your condition as best as you can" or even "you may be fired if your employer ever learnt of your condition". These were unfortunate and shocking statistics, but after visiting the farms with blueberries in Kanazawa and visiting Share Kanazawa, I became very positive for their activities bridging the gap between fellow citizens. I commend them on their work so far, and hope that a focus on community-immersion will help them work towards urban sustainability".

\section{Discussion}

As a result of the field trips, the students observed the interconnection of the Environmental-Business-Social Sustainability, and found out that the implementation of a community-based strategy to the business management system could positively influence sustainable urban development. The largest value that is observed in Japanese companies for social contributions is that the business sectors while providing the social welfare do not overuse or overexploit the natural resources and ecosystem services. In reverse, in most of the cases they go in parallel, contributing to the society while preserving the natural biodiversity. For example, the case with the Blueberry farming was to provide the job opportunities for the disabled kids, together with the regional revitalization of the abandoned farmlands.

Another student emphasised the importance of the capital to reach sustainability, and underlined that business for welfare could create the shared values to reach sustainability by contributing to financial sectors and providing employment opportunities. "Something that I did not expect to learn from this course was that the driving force for making changes for urban sustainability is the capital. Sustainability is not possible without the proper funding, and informed allocation of the given budget. The thing that welfare business showed is that considering the benefits for the communities with good intentions would be the driving force in making the world more sustainable. And although this is still somewhat true, a good intention itself is powerless without the proper capital. Pursuing only the personal financial income alone can be dangerous in the wrong hands, and in reverse providing only welfare activities is useless without any 
means of implementation. Only when the two come together, like combination of business activities with the implementation of the community-based welfare practices and care can make progress towards urban sustainability.

Our field trips showed that "sustainability is not the same as conservation or preservation. It does not mean not to use resources, but to manage the limited resources we have in such a way that will not be detrimental to the environment. Sustainability is not just about environmental or natural resources but people. A city or community that has no people is not sustainable because there is no one to make use of resources". Another student discussed how the perception of the sustainability changes after the fieldwork: "When thinking about sustainability in Japan, I used to only limit my scope to how Japan can make better recycling policies or produce more eco-friendly technology, for example. I did not realise that the aging population and low birth rates were also very much important aspects of sustainability and well-being. We have to care about the well-being of elderly as much as we do children and adults who are at the age to start families in order to sustain existing cities, or create new sustaining communities. While Japan is continuously developing an advanced technology to make people's lives more convenient and to prolong our lives, by the rate of population decline, these technological developments would serve no purpose if there were not enough people to use it."

Field trips in the welfare sectors showed the interconnection of human well-being with all other environmental sectors. One student stated, "Well-being is not just the condition of wellness on an individual basis. Well-being is not limited to personal health. This is affected by many factors and institutions outside of ourselves in the society. It is affected by where food comes from, what water, soil, or resources were used to cultivate that food, who is employed to pick our food and process it, how our water is treated to be drinkable when disseminated through city pipes, the recycle centres, land-fills, and places where our waste goes, the institutions that include all members of society from young to old, abled to disabled, etc. These are all issues that need to be addressed because they affect the physical, mental, and psychological well-being of a culture, a collective population of people who are susceptible to the same risks because of similar experiences or circumstances."

These field trips were conducted as the pilot study to evaluate the teaching methods for urban sustainable development through the welfare business sectors. In future, the author intends to improve the methodology with quantitative data analysis.

\section{Conclusion}

In this study, the author has conducted the field trips in the small-scaled private and town-scaled business sectors to observe the interconnection of urban sustainability practices through the welfare with environmental, social and economic sectors. In total, four welfare sectors were visited by 15 international students. Field trips helped the students independently analyse the urban issues and raise the questions towards the sustainable, safe and inclusive cities. Besides, field trips raised the awareness on the complexity of the sustainability practice and interconnection of all urban sectors with each other.

Higher education bears the responsibility for educating the future global citizens and new generations with a wide range of viewpoints, developing the ability for independent 
and critical thinking and increasing students' own potential by becoming self-actualized members of the society. Some researchers have already analysed the importance of the sustainability strategic plans at the curriculum level of higher education and encouraged students to be more engaged in the issues that will shape their future (Smith, 2011). Besides, re-orienting the teaching and learning practices towards the critical and transformative pedagogy can provide the opportunity for the teachers to construct the pedagogical environment, where they can directly communicate with the learners (Kostoulas-Makrakis, 2010), society, natural environment (Mandolini, 2007) and the local communities during the field trips.

In the present study, education in the welfare sectors helped the students analyse not only the sustainable sectors, but also realise the function of human rights and involvement of the government which would take the responsibility for the concept of the inclusive and global citizenship (Miedema \& Bertram-Troost, 2015). The author has introduced the qualitative transdisciplinary field trip approach and presented the complexity of the sustainability concept. Especially the field trips in the town-scaled welfare sectors have shown the effective method to address the sustainability issues within the complexity of the system. However, to improve the methodological approach to the author will perform a cohort analysis with a quantitative data analysis in the further study.

\section{References}

Aida, M., \& Iida, Y. (2016). Development of educational fieldwork activities for the international students: Case of awareness raising in biocultural diversity of Kanazawa City. Research Bulletin of Kanazawa University International Student Exchange Centre, 19, 88-106.

Ando, S., Yamaguchi, S., Aoki, Y., \& Thornicroft, G. (2013). Review of mental-healthrelated stigma in Japan. Psychiatry and Clinical Neurosciences, 67(7), 471-482.

D'amato, A., Henderson, S., \& Florence, S. (2009). Corporate social responsibility and sustainable business. A Guide to Leadership Tasks and Functions, 102.

Hawken, P. (2010). The Ecology of Commerce: A Declaration of Sustainability (Revised Edition). New York: Harper Collins.

Kostoulas-Makrakis, N. (2010). Developing and applying a critical and transformative model to address ESD in teacher education. Journal of Teacher Education for Sustainability, 12(2), 17-26.

Mammadova, A. (2016). Sustainable Development Goals: Learning from Kanazawa City. 1-48.

Mandolini, C. (2007). Conditions, processes, and aims of teacher education: A philosophical perspective. Journal of Teacher Education for Sustainability, 7, 5-13.

Miedema, S., \& Bertram-Troost, G. (2015). The Challenges of global citizenship for worldview education. The perspective of social sustainability. Journal of Teacher Education for Sustainability, 17(2), 44-52.

Murray, P. (2011). The sustainable self: A personal approach to sustainability education. Routledge.

Nonaka, I., \& Takeuchi, H. (1995). The knowledge-creating company: How Japanese companies create the dynamics of innovation. Oxford University Press. 
Pipere, A. (2016). Envisioning complexity: Towards a new conceptualization of educational research for sustainability. Discourse and Communication for Sustainable Education, 7(2), 68-91. doi: 10.1515/dcse-2016-0017

Porter, E. M., \& Kramer, M. R. (2011). Creating Shared Value. Harvard Business Review, Jan-Feb.

Robertson, M. (2014). Sustainability principles and practice. Routledge.

Salìte, I., Drelinga, E., Iliško, Dz., Zariņa, S., \& Oḷehnoviča, E. (2016). Sustainability from the transdisciplinary perspective: An action research strategy for continuing education course development. Journal of Teacher Education for Sustainability, 17(2). SCOPUS ISSN (Online), 1691-5534. doi: 10.1515/jtes-2016-0020

Smith, G. (2011). Developing a sustainability plan at a large US College of Education. Journal of Teacher Education for Sustainability, 13(2), 5-16.

Sommerville, M. A., \& Rapport, D. J. (Eds.) (2002). Transdisciplinarity: Recreating integrated knowledge. Montreal QC, Canada: McGill-Queens University Press.

Tanimoto, K., \& Suzuki, K. (2005). Corporate social responsibility in Japan: Analyzing the participating companies in global reporting initiative. Stockholm School of Economics, EIJS, Working Paper 208, 3.

Wals, A. E., \& Jickling, B. (2002). "Sustainability" in higher education: From doublethink and newspeak to critical thinking and meaningful learning. International Journal of Sustainability in Higher Education, 3(3), 221-232.

Correspondence concerning this paper should be addressed to Aida Mammadova, Assistant Professor, Kanazawa University, General Education Hall, KakumaMachi, Kanazawa City, Ishikawa Prefecture, 920-1192, Japan. Email: mammadova@staff.kanazawa-u.ac.jp 